\title{
Robos and Slits Control the Pathfinding and Targeting of Mouse Olfactory Sensory Axons
}

\author{
Kim T. Nguyen-Ba-Charvet, ${ }^{1,2}$ Thomas Di Meglio, ${ }^{1,2}$ Coralie Fouquet, ${ }^{1,2}$ and Alain Chédotal ${ }^{1,2,3}$ \\ ${ }^{1}$ Université Pierre et Marie Curie and ${ }^{2}$ Centre National de la Recherche Scientifique, Unité Mixte de Recherche 7102, F-75005 Paris, France, and ${ }^{3}$ Assistance \\ Publique-Hôpitaux de Paris, Groupe Hospitalier Pitié-Salpêtrière, Fédération de Neurologie, F-75013 Paris, France
}

\begin{abstract}
Odorants are detected by olfactory receptor neurons (ORNs) located in the olfactory epithelium. In mice, ORNs expressing the same odorant receptor (OR) project to a single glomerulus out of 1800 in the olfactory bulb (OB). It has been proposed that OR-derived cAMP signals guide ORN axons to their glomeruli rather than OR themselves. Recently, it has also been shown that the axon guidance molecule Slit1 and its receptor Robo2 control the dorsoventral segregation of ORN axons as they are projecting to the OB. We have analyzed the development of olfactory projections in Slit1/Slit2 and Robo1/Robo2 single and double mutants. We show that in Robo1 ${ }^{-1-}$;Robo ${ }^{-1-}$ mice, most ORN axons fail to enter the OB and instead project caudally into the diencephalon. Moreover, in these mice, ORN axons expressing the same OR project to several glomeruli at ectopic positions. Thus, Slit1, Slit2, Robo1, and Robo2 cooperate to control the convergence of $\mathrm{ORN}$ axons to the $\mathrm{OB}$ and the precise targeting of $\mathrm{ORN}$ axons to specific glomeruli.
\end{abstract}

Key words: Slit; Roundabout; axon guidance; glomerulus; olfactory sensory neuron; olfactory epithelium

\section{Introduction}

In the olfactory epithelium, olfactory receptor neurons (ORNs) expressing a given odorant receptor (OR) project to only a single glomerulus on the medial and lateral parts of the olfactory bulb (OB) (Mombaerts et al., 1996). Glomeruli are microdomains of the $\mathrm{OB}$, forming spherical structures where OR axons synapse on the dendrites of mitral and tufted cells. The spatial position of each glomerulus, also called the glomerular map, is highly conserved between animals of the same species, although their final morphology varies (Komiyama and Luo, 2006). In the embryonic mouse, the final/mature glomerular pattern emerges around the first postnatal days (Royal and Key, 1999). In mouse, little is known about the molecules that are controlling glomerulus targeting (Cutforth et al., 2003; Schwarting et al., 2004; Serizawa et al., 2006). However, it has been demonstrated that OR-derived cAMP signals guide ORN axons to their glomeruli rather than ORs themselves (Imai et al., 2006; Chesler et al., 2007). It has also recently been shown that Slit 1 and its receptor Robo 2 influence the dorsoventral segregation of ORN axons in the OB (Cho et al., 2007). Here, we analyzed the development of ORN axons in Slit1/ Slit2 and Robo1/Robo2 single and double mutants. A striking phenotype of Robo1/Robo 2 knock-out mice is that most ORN axons do not invade properly their target territory in the OB, to project

Received Dec. 21, 2007; revised Feb. 18, 2008; accepted March 13, 2008.

This work was supported by an "Equipe FRM" grant from the Fondation pour la Recherche Médicale and by the Association pour la Recherche contre le Cancer. We thank Dr. M. Tessier-Lavigne for providing Slit- and Robodeficient mice, Dr. H. Breer for anti-MOR256-17 antibody, Dr. F. Margolis for the anti-OMP, Dr. F. Murakami for the anti-Rob02, V. Cannaya for excellent technical assistance, and R. Schwartzman for confocal imaging. We are grateful to Dr. J.-F. Cloutier for helpful comments on this manuscript.

Correspondence should be addressed to Alain Chédotal at his present address: Institut de la Vision, Inserm, Unité Mixte de Recherche S592, 17 rue Moreau, F-75012 Paris, France. E-mail: alain.chedota@@inserm.fr.

D0I:10.1523/JNEUROSCI.5671-07.2008

Copyright $\odot 2008$ Society for Neuroscience $\quad 0270-6474 / 08 / 284244-06 \$ 15.00 / 0$ more caudally into the diencephalon. Furthermore, in Slit $1^{-/-}$; Slit $2^{-1-}$, Robo $2^{-1-}$, or Robo1 ${ }^{-1-}$;Robo $2^{-1-}$ mice, ORN axons expressing the same OR project to supernumerary and ectopic glomeruli. Our findings provide strong evidence that Slit1, Slit2, Robo1, and Robo 2 cooperate to control the coalescence of ORN projections to the $\mathrm{OB}$ and the accurate targeting of ORN axons to specific glomeruli.

\section{Materials and Methods}

Animals. Slit-deficient mice and Robo-deficient mice were generated and genotyped as described previously (Plump et al., 2002; Grieshammer et al., 2004; Ma and Tessier-Lavigne, 2007). The day of vaginal plug is embryonic day 0 (E0). All experimental procedures were performed in accordance with European Union guidelines.

Binding studies. Binding was performed as described by Fouquet et al. (2007).

Immunocytochemistry. Embryos and mice were processed as described previously (Fouquet et al., 2007). The primary antibodies used were rabbit anti-GFP (Invitrogen, Carlsbad, CA), anti-p75 (Millipore Bioscience Research Reagents, Temecula, CA), anti- $\beta$-galactosidase (Cappel; MP Biomedicals, Solon, OH), anti-Robo2 (gift from Dr. F. Murakami, Osaka University, Osaka, Japan), anti-olfactory marker protein (OMP; gift from Dr. F. Margolis, Johns Hopkins University School of Medicine, Baltimore, MD), anti-MOR256-17 (gift from Dr. H. Breer, University of Hohenheim, Stuttgart, Germany), goat anti-Robol (R\&D Systems, Minneapolis, MN), anti-Robo2 (R\&D Systems), mouse antiGAP43 (91E12; Millipore Bioscience Research Reagents), anti-O4 (Millipore Bioscience Research Reagents), and rat anti-L1 (Millipore Bioscience Research Reagents), followed by species-specific secondary antibodies [Cy3-conjugated from Jackson ImmunoResearch (West Grove, PA) or Alexa Fluor 488 from Invitrogen], counterstained with Hoechst 33258 (10 $\mu \mathrm{g} / \mathrm{ml}$; Sigma-Aldrich, St. Louis, MO) and examined under a fluorescent microscope (DMR; Leica, Wetzlar, Germany) or a confocal microscope (SP5; Leica).

DiI tracing. ORN projections were labeled with $1,1^{\prime}$-dioctadecyl- 


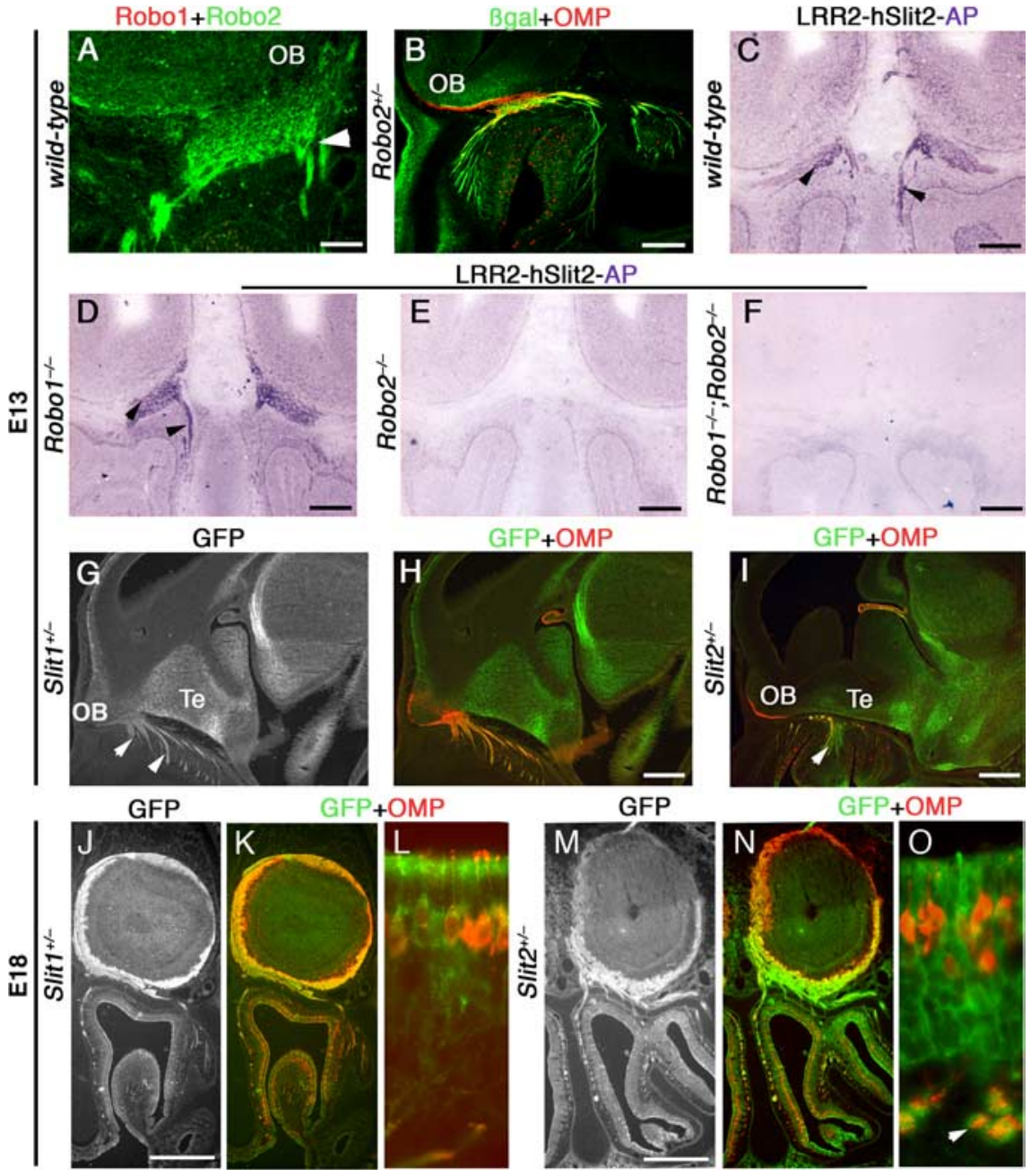

Figure 1. Slit1, Slit2, and Robo2 are expressed in ORN axons. $\boldsymbol{A}$, Coronal section of E13 wild-type forehead immunostained for Rob02 and Robo1. Only Robo2 is expressed in the olfactory nerve (arrowhead). B, Sagittal section of E13 Robo2 $2^{+/}$head immunostained with anti- $\beta$-galactosidase and anti-0MP. ORN axons express both markers and project rostrally to the OB. $\boldsymbol{C}-\boldsymbol{F}$, LRR2-hSlit2-AP binding on coronal sections of E13 foreheads. LRR2-hSlit2-AP binds to olfactory nerves (arrowheads) of wild-type $(\boldsymbol{C})$ and Robo1 $1^{-1-}(\boldsymbol{D})$ mice, but not of Robo2 $2^{-1-}(\boldsymbol{E})$ or Robo1 $1^{-1-} ;$ Robo2 $2^{-1-}(\boldsymbol{F})$ embryos. G-I, Sagittal section of foreheads from E13 Slit ${ }^{+/-}(\mathbf{G}, \boldsymbol{H})$ or Slit2 $2^{+/-}(\boldsymbol{I})$ mice. $\boldsymbol{H}$, In Slit1 ${ }^{+/-}$, GFP is highly expressed in the basal telencephalon (Te), a region avoided by OMP-positive ORN axons. G, ORN axons also expressed GFP (arrowheads). I, Likewise, in Slit2 ${ }^{+/-}$embry0s, ORN axons coexpress OMP and GFP (arrowhead) and avoid the basal telencephalon, where GFP is highly expressed. $\boldsymbol{J}-\mathbf{0}$, Coronal sections of Slit1 $^{+/-}(\boldsymbol{J}-\boldsymbol{L})$ and Slit2 $2^{+/-}(\boldsymbol{M}-\mathbf{0})$ E18 embryos. $\boldsymbol{J}, \boldsymbol{K}, \mathrm{GFP}$ is expressed in the olfactory nerve layer (ONL) in the OB and ORNs in the epithelium. $\boldsymbol{L}$, GFP-positive cells in the olfactory epithelium also express OMP. $\boldsymbol{M}, \boldsymbol{N}, \mathrm{GFP}$ is coexpressed with OMP in the ONL of Slit2 ${ }^{+/-}$embryo. $\boldsymbol{O}$, In the olfactory epithelium, all cells express GFP, including OMP-positive ORNs and their axons (arrowhead). Scale bars: $\boldsymbol{A}, 100 \mu \mathrm{m} ; \boldsymbol{B}-\boldsymbol{F}, \boldsymbol{H}$ (for $\boldsymbol{G}, \boldsymbol{H}$ ), $\boldsymbol{I}, 200 \mu \mathrm{m} ; \boldsymbol{J}$ (for $\boldsymbol{J}-\boldsymbol{L}$ ), $\boldsymbol{M}$ (for $\boldsymbol{M}-\mathbf{0}), 500 \mu \mathrm{m}$.

$3,3,3^{\prime}, 3^{\prime}$-tetramethylindocarbocyanine perchlorate (DiI; Invitrogen) as described previously (de Castro et al., 1999). Injected heads were cut in $80 \mu \mathrm{m}$ sections with a vibratome (Leica). Sections were counterstained with Hoescht (Sigma-Aldrich).

\section{Results}

\section{Developing ORNs express Robo2, Slit1, and Slit2}

To determine whether ORNs express Robo receptors, we used immunohistochemistry and previously characterized mouse knock-out lines that express $\beta$-galactosidase under the Robol or Robo2 (Grieshammer et al., 2004; Fouquet et al., 2007) promoters. At E13, ORN axons were strongly immunoreactive for Robo2 but not Robol (Fig. $1 A$ and data not shown). Accordingly, $\beta$-galactosidase was expressed by ORNs of Robo $2^{+/-}$mice but not Robol $^{+/-}$mice (Fig. $1 B$ and data not shown). Although the expression of $\beta$-galactosidase is not indicative of the presence of the endogenous Robo protein, these data together with Robol and Robo2 immunolabeling suggest that a subset of ORN neurons expresses Robo2.

To confirm that at E13 Robo2 was the only Slit receptor expressed by ORN axons, we performed binding studies using a recombinant protein comprising the second leucine-rich repeat region of Slit2 fused to alkaline-phosphatase (LRR2hSlit2-AP) (Fouquet et al., 2007). LRR2hSlit2-AP proteins bound to E13 ORN axons from wild-type (Fig. 1C) and Robo1 $^{-1-}$ (Fig. 1D) mice, but no staining was observed in Robo2 $2^{-1-}$ (Fig. 1E) and Robo1 $^{-I-}$;Robo2 ${ }^{-1-}$ (Fig. 1 F) mice. Overall, these results show that developing ORN axons only express Robo2. This expression pattern was unchanged at least until E18 (data not shown).

Slit1 and Slit2 mRNAs are known to be expressed in the basal forebrain and septum region (Nguyen-Ba-Charvet et al., 1999; Marillat et al., 2002), and accordingly GFP was highly expressed in these territories in Slit $1^{+/-}$and Slit2 ${ }^{+/-}$E13 embryos (Fig. 1G-I). Interestingly, GFP was also detected in ORN cell bodies and their axons (Fig. $1 G-I, L, O$ ). In the $\mathrm{OB}$ of E18 Slit $1^{+/-}$and Slit2 ${ }^{+/-}$mice, GFP and OMP labeling was observed in the olfactory nerve layer and OMP neurons in the olfactory epithelium (Fig. $1 J-O$ ). The presence of GFP in ORN axons does not imply that Slit1 and Slit2 are expressed in this cellular compartment, but our results and others (Cho et al., 2007) suggest that developing ORN neurons express Slit1 and Slit 2 and also that their axons grow under the telencephalon around a region that expresses a high level of Slit 1 and Slit2.

In contrast, ORNs were not immunoreactive for Robol in wild-type mice (Fig. $2 A)$ or $\beta$-galactosidase in Robo1 ${ }^{+/-}$mice (Fig. $2 B$ ). However, $\beta$-galactosidase was detected in $\mathrm{O}_{4}{ }^{+}$cells (Fig. $2 C$ ), and Robo 1 was coexpressed with $\mathrm{p} 75^{+}$in cells surrounding ORN axons (Fig. $2 D, E$ ), most likely corresponding to olfactory ensheathing cells (OECs) (Ramon-Cueto and Nieto-Sampedro, 1992). These Robo1expressing cells wrapped around ORN axons (Fig. $2 F, G$ ) before they enter the OB. At E18, $\beta$-galactosidase was still expressed by ORNs, but some did not coexpress OMP and vice versa (Fig. $2 H-J)$.

\section{Defasciculation and ectopic projection of ORN axons}

To determine whether Slit/Robo signaling plays a role in ORN axon guidance, we examined the trajectories of ORN axons in Robo1 and/or Robo2 and Slit1 and/or Slit2 knock-out mice. As described before, Robo2 ${ }^{-1-}$, Robo1 $^{-1-} ;$ Robo2 $^{-1-}$, Slit2 $^{-1-}$, and Slit ${ }^{-1-}$;Slit $2^{-1-}$ mice die at birth (Plump et al., 2002; Ma and Tessier-Lavigne, 2007); thus, ORN postnatal development could not be studied in these knock-outs. At E16-E18, ORNs strongly 

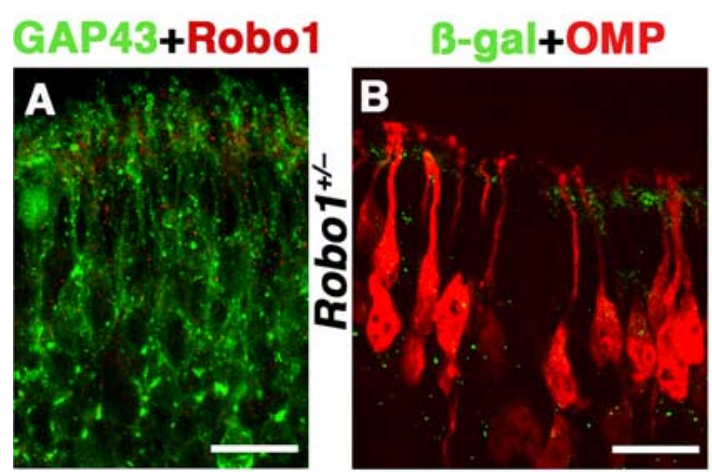

B-gal+Robo1
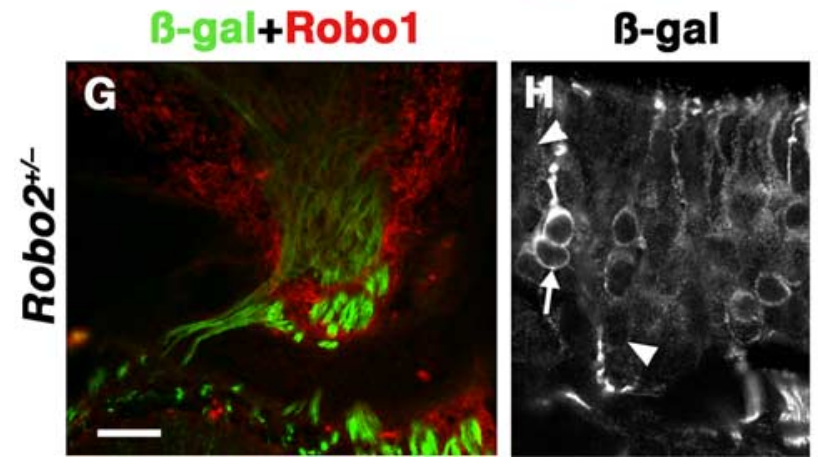

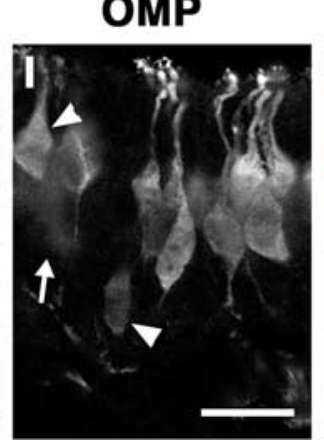

$\mathrm{Bgal}+04$ + Hoescht
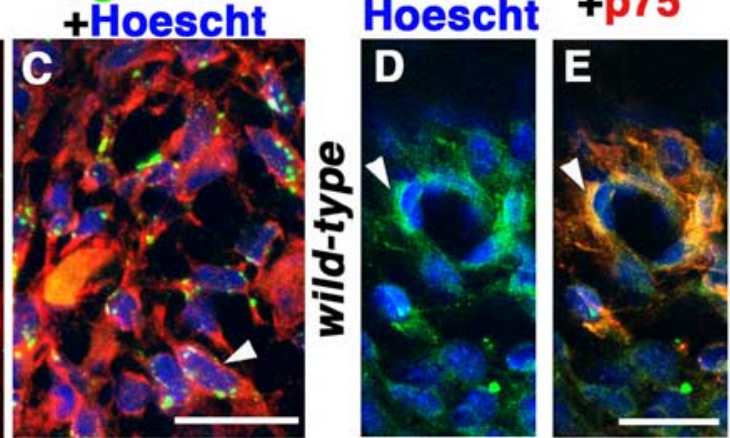

B-gal+OMP

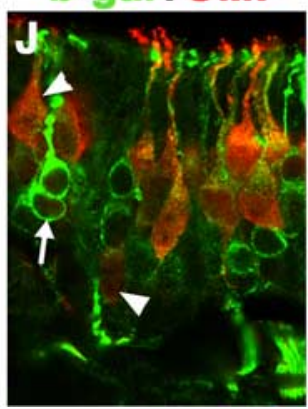

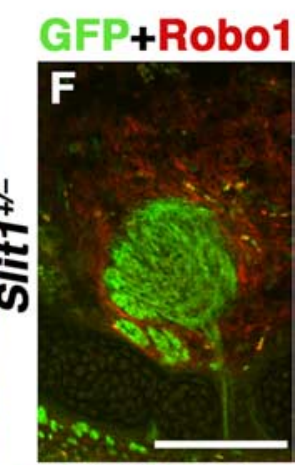

MOR256-17
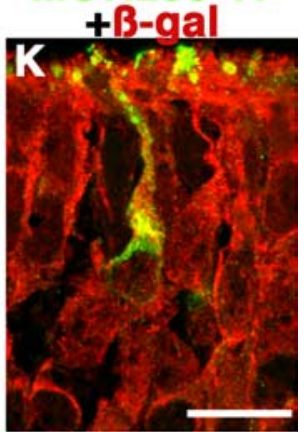

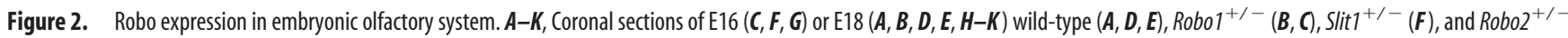
$(\mathbf{G}-\boldsymbol{K})$ embryos. $\boldsymbol{A}, \mathrm{GAP}_{3} 3^{+}$ORNs are not Robo $1^{+}$. $\boldsymbol{B}, \boldsymbol{C}$, Likewise, in Robo $1^{+/-}$mice, $\beta$-galactosidase is not detected in $0 \mathrm{MP}{ }^{+}$ORNs, but is present in $04^{+}$cells (confocal image, $\left.3 \mu \mathrm{m}\right) . \boldsymbol{D}, \boldsymbol{E}$, p75-expressing cells are immunoreactive for Robo1 ( $3 \mu \mathrm{m}$ confocal image). $\boldsymbol{F}$, In Slit1 ${ }^{+/-}$mice, GFP ${ }^{+}$ORN axons are surrounded by Robo $1^{+}$cells. $G, \ln R o b o 2^{+/-}$embryo, $\beta$-galactosidase ${ }^{+}$ ORN axons are surrounded by Robo $1^{+}$cells. $\mathbf{G}-\boldsymbol{K}, \ln R o b 02^{+/-}$embryos, $\beta$-galactosidase $(\boldsymbol{H}, \boldsymbol{J})$ is expressed with OMP $(\boldsymbol{I}, \boldsymbol{J})$ in ORNs. Note that some 0MP neurons do not coexpress $\beta$-galactosidase (arrowheads) and vice versa (arrow). $\boldsymbol{K}, 0$ RNs expressing $\beta$-galactosidase in Robo2 ${ }^{+/-}$embryos are also immunoreactive for MOR256-17. Scale bars: $\boldsymbol{A}, \boldsymbol{B}, \boldsymbol{I}(\boldsymbol{H}-\boldsymbol{J}), 15 \mu \mathrm{m} ; \boldsymbol{C}, \boldsymbol{E}$ (for $\boldsymbol{D}, \boldsymbol{E}), 20 \mu \mathrm{m} ; \boldsymbol{F}, 200 \mu \mathrm{m} ; \boldsymbol{G}, 75 \mu \mathrm{m} ; \boldsymbol{K}, 10 \mu \mathrm{m}$.

express the OMP (Farbman and Margolis, 1980) (Fig. 2I-J). In E16 and E18 wild-type mice $(n=3)$, all Slit (Slit1, $n=4 ;$ Slit2, $n=$ 1; Slit1/2, $n=6$ ) or Robo (Robo1, $n=2$; Robo2, $n=2$; Robo1/2, $n=1$ ) single and double heterozygous mice, and Slit ${ }^{-1-}$ mutants $(n=5)$, OMP-positive axons projected, fasciculated, from the olfactory epithelium to the base of the telencephalon before turning rostrally toward the $\mathrm{OB}$ and terminated in the glomerular layer (Fig. $3 A, B$ and data not shown). In Slit ${ }^{-1-}$;Slit $2^{-1-}$ mice $(n=3)$, all OMP-positive axons reached the OB and formed protoglomeruli, but the olfactory nerve was slightly defasciculated (Fig. 3C). In contrast, in Robo $2^{-1-}$ mice $(n=5)$, most axons reached the ONL but seemed unable to cover the ventral OB (supplemental Fig. 1, available at www.jneurosci.org as supplemental material). Some bundles were stuck under the $\mathrm{OB}$ and in the ONL. Nevertheless, ORN axons that entered the OB form protoglomeruli. In addition, ectopic ORN axon bundles were also detected outside the $\mathrm{OB}$ in more lateral territories (supplemental Fig. 1, available at www.jneurosci.org as supplemental material). ORN axon pathfinding defects were much more severe in Robo1 ${ }^{-1-} ;$ Robo $^{-l-}$ mice (E13, $n=3 ; \mathrm{E} 16, n=2$; E18, $\left.n=5\right)$. At E13, an abnormal accumulation of ORN axons under the ventral telencephalon was observed (data not shown). From E16 to E18, OMP staining showed that some ORN axon bundles turned caudally and grew under the surface of the telencephalon (Fig. $3 D-F$ ), but a majority entered the brain ventrally to invade and arborize in the medial septum (Fig. $3 D, E$ ). Moreover, the olfactory nerve was fragmented in multiple axon bundles (Fig. $3 F$ ). Thus, in absence of Robo/Slit signaling, a majority of ORN axons is unable to innervate the $\mathrm{OB}$.
Slit and Robo mutants present MOR256-17 ectopic glomeruli Next, we used an antibody that recognizes a single olfactory receptor called MOR256-17 (Strotmann et al., 2004) (none of the other receptor-specific antibodies we used labeled embryonic OR axons). In adult wild-type mouse, MOR256-17 ${ }^{+}$ORN axons project to a dorsolateral glomerulus and a medioventral one, per OB. At E18, we observed the same MOR256-17 pattern in wildtype animals (Fig. 4A-D). Double labeling on Robo2 knock-outs showed that MOR256-17-positive ORNs were immunoreactive for $\beta$-galactosidase (Fig. $2 K$ ), suggesting that they expressed Robo2. Next, OBs from Slit1 and/or Slit2 and Robo1 and/or Robo2 mutants were immunostained for OMP and MOR256-17. We then counted the number of labeled glomeruli and analyzed their position (Fig. 4). The MOR256-17 glomerular pattern was similar in wild-type $(n=8 \mathrm{OB} ; 1 \pm 0$ mean number of lateral or medial glomeruli) and in Slit $1^{-1-}(n=6 ; 1.2 \pm 0.2$ lateral; $1 \pm 0$ medial), Slit2 ${ }^{-l-}(n=6$; lateral, $1.3 \pm 0.2$; medial, $1.3 \pm 0.4)$, Robo $^{-1-}(n=6$; lateral, $1.2 \pm 0.2 ;$ medial, $1 \pm 0)$ and Robo2 ${ }^{-1-}$ $(n=6$; lateral, $1.2 \pm 0.2$; medial, $1.3 \pm 0.2)$ mice (Fig. $4 A-H)$. In contrast, MOR256-17 glomerular pattern was perturbed in Slit $1^{-/-}$;Slit $2^{+/-}$mice (4/4 cases) as two lateral glomeruli instead of one were observed $(2 \pm 0 ; p<0.01)$. In Slit $1^{-1-} ;$ Slit $^{-1-}$ mutant, three lateral glomeruli were observed (6/8 cases; $2.8 \pm$ $0.3 ; p<0.01)$ and two median glomeruli ( $5 / 8$ cases; $1.6 \pm 0.2 ; p<$ 0.05 ) (Fig. $4 I, J)$. The distance between these glomeruli varies from 70 to $500 \mu \mathrm{m}$, and they appeared a little smaller than the wild-type ones. Confocal microscopy analysis of OMP/ MOR256-17 double labeling showed that even in mutant animals, the MOR256-17 glomeruli only contain MOR256-17- 
OMP+Hoechst

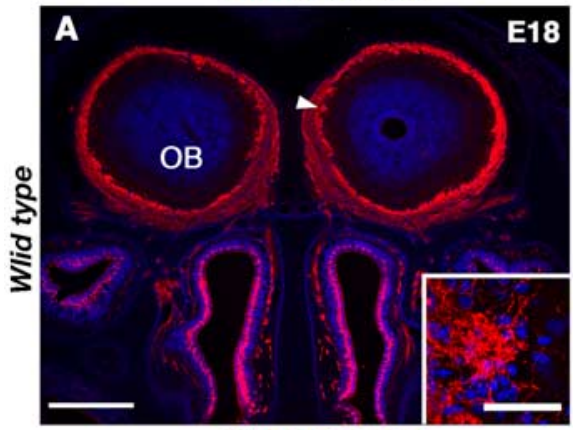

OMP+Hoechst

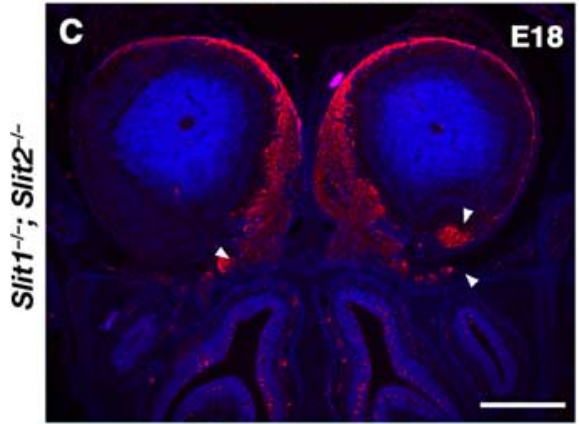

OMP+Hoechst

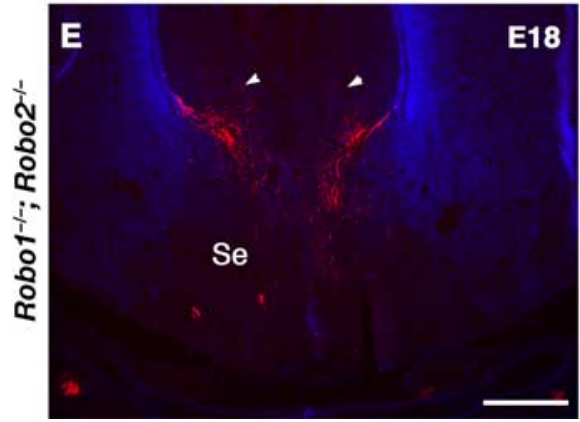

Figure 3. ORN axon pathfinding defects in Slit and Robo mutants. $A-F, 0 M P$ immunolabeling of $E 18$ coronal $(A, C, E, F)$ and sagittal $(\boldsymbol{B}, \boldsymbol{D})$ sections of $\mathrm{E} 16(\boldsymbol{B}, \boldsymbol{D})$ and $\mathrm{E} 18(\boldsymbol{A}, \boldsymbol{C}, \boldsymbol{E}, \boldsymbol{F})$ embryos. $\boldsymbol{A}$, In wild-type brain, $0 \mathrm{RN}$ axons cover the whole surface of the $O B$ surface and start forming glomeruli. The arrowhead indicates a glomerulus shown at a higher magnification in the inset. Scale bar (in inset), $50 \mu \mathrm{m} . \boldsymbol{B}, \operatorname{In} \mathrm{Robo1}^{+/-} ; \mathrm{Robo2}^{+/-}$embryos, $0 \mathrm{MP}^{+}$ORN axons project rostrally to cover the entire surface of the OB. C, In Slit $1^{-1-} ;$ Slit2 ${ }^{-1-}$ embryos, OMP axons also project to the $\mathrm{OB}$ and form glomeruli, but the olfactory nerve is slightly defasciculated (arrowheads). D, In Robo $1^{-1-} ;$ Robo2 $2^{-1-}$ embryos, only a few OMP axons reach the $\mathrm{OB}$, but most of them coalesce under the forebrain before taking a caudal route or invading the septum (SE). $\boldsymbol{E}, \boldsymbol{F}, \operatorname{In} R o b 01^{-1-} ; R \circ o b 02^{-1-}$ embryos, $\mathrm{OMP}^{+}$axons are unable to cover the $\mathrm{OB}$ and do not all form clear glomeruli. $\boldsymbol{F}$, The olfactory nerve is fragmented in smaller fascicles that are spread laterally. In addition, many ORN axons project into the septum ( $\boldsymbol{E}$, arrowheads). Scale bars, $500 \mu \mathrm{m}$.

positive axons (supplemental Fig. 2, available at www. jneurosci.org as supplemental material), suggesting that a duplication/multiplication of MOR256-17 glomeruli has occurred rather than an ectopic invasion by MOR256-17 ORN axons of MOR256-17-negative neighboring glomeruli. The phenotype was similar in Robo1 ${ }^{-1-} ;$ Robo $2^{-1-}$ mutants, but the number of ectopic glomeruli varied from three lateral and two medial glomeruli $(2 / 6$ cases $)$ to two lateral and one medial glomeruli $(4 / 6$ cases, mean number of lateral glomeruli, $2.3 \pm 0.3 ; p<0.05$ ) (Fig. $4 K, L)$.

In mammals, the olfactory projection is uncrossed: ORN axons from one side of the epithelium target the OB located on the same side. As Slit/Robo signaling is known to control the development of commissural projections in many systems (Dickson and Gilestro, 2006), the ectopic glomeruli could contain ORN axons coming from the contralateral olfactory epithelium. To rule out this possibility, a small injection of DiI was performed in one OB. In both wild-type $(n=4)$ and $R o b o 1^{-1-}$; Robo2 $^{-1-}(n=2)$ mutants, retrogradely DiI-labeled ORNs were only detected on the ipsilateral side (supplemental Fig. 3, available at www.jneurosci.org as supplemental material). Therefore, ORN projections remain ipsilateral in absence of Slit/ Robo signaling.

Although the glomerular pattern is set just after birth, the initial projection is more exuberant and postnatal refinements occur until P60 (Zou et al., 2004). To determine whether additional glomeruli were still observed after the refinement period, older Slit $1^{-1-}$ and Slit ${ }^{-1-}$;Slit2 ${ }^{+/-}$ mice were studied (P60 to P90). In adults at E18, two MOR256-17 lateral glomeruli were found in the OB of Slit ${ }^{-/-}$;Slit2 ${ }^{+/-}$ adult (P90) mice ( $3 / 3$ cases) (Fig. $4 M, N)$, instead of one in Slit1 ${ }^{+/-}(n=2)$ (Fig. 4O) and Slit $1^{-1-}(n=3)$ (Fig. $\left.4 P\right)$ mice. Nevertheless, no ectopic medial glomeruli were observed. This suggests that glomerular multiplication could be maintained, at least partially, throughout life in Slit and Robo knock-out mice.

\section{Discussion}

We show here that Slit1, Slit2, and Robo2 are expressed by ORNs and Robol by OECs. Furthermore, we demonstrate that Robo2 is necessary for axons to converge to the OB, whereas Slit1, Slit2, and Robo2 are required by ORN axons to project to a single glomerulus. A role for Slits and Robos in the development of ORNs was first demonstrated in Drosophila (Jhaveri et al., 2004), where the projection pattern of ORN axons in the glomeruli is controlled by three Robos. Our results show that in mouse, Robos guide ORN axons to their target area and that in their absence many ORN axons fail to reach the OB. Although we did not find a combinatorial code of Robos differentiating subtypes of ORN axons, our data and others show that Robo2 is not expressed by all ORNs (Cho et al., 2007). Therefore, one could easily imagine that Robo2-positive ORN axons express an additional combination of axon guidance receptors. A recent analysis of Slit1 and Robo2 mutant mice showed that they are required for the zonal segregation of ORN axons and that Robo2 ${ }^{-1-}$ OB lack ventral innervation (Cho et al., 2007). Using other markers, we confirmed that Robo2-deficient ORN axons are unable to enter the ventral $\mathrm{OB}$ and found that the missing axons project into the septum. Interestingly, ORN axon guidance defects are more pronounced in $R o b o 1^{-1-} ; R_{0 b o} 2^{-1-}$ mutants than in Robo2 $2^{-I-}$ mice, although ORNs do not express Robo1. This result suggests a non-cell-autonomous function for Robo1 in axon guidance, as previously proposed in Drosophila (Kraut and Zinn, 2004). In vitro studies have shown that OECs provide a good substrate for ORN axons (Kafitz and Greer, 1999). Thus, 
Robol expression on OECs may influence ORN axon guidance, by binding to Robo2, or Slits, if those latest are expressed by ORN axons.

The possible presence of Slit1 and Slit2 in ORN axons may also influence their synaptic partners in the $\mathrm{OB}$, the mitral and tufted cells, which are known to express Robo2 (Nguyen-Ba-Charvet et al., 1999; Cho et al., 2007; Fouquet et al., 2007). Therefore, a simple repulsive model cannot probably fully explain Slit/Robo mode of action in primary olfactory projections.

In addition to guiding ORN axons to their appropriate target in the OB, Slit/ Robo also control the development of the lateral olfactory tract (Nguyen-BaCharvet et al., 2002; Fouquet et al., 2007) and the migration of $\mathrm{OB}$ interneurons (Wu et al., 1999; Nguyen-Ba-Charvet et al., 2004). This suggests that some of the defects described here for primary olfactory axons may be somehow secondary and attributed to mechanisms other than Slit/Robo expression by ORN axons. Vice versa, the reduced size of the OB in Robol/ Robo2 and Slit1/Slit2 double mutants, which was attributed to a reduction of $\mathrm{OB}$ interneurons (Bagri et al., 2002; Sawamoto et al., 2006), could be at least in part caused by the mistargeting of ORN axons, because $\mathrm{OB}$ development is known to require olfactory axons (Monti-Graziadei and Graziadei, 1992).

The correct pathfinding of ORN axons requires OR-cAMP signaling (Imai et al., 2006; Chesler et al., 2007). Likewise, the repulsive activity of Slits is known to be regulated by cyclic nucleotides (NguyenBa-Charvet et al., 2001; Chalasani et al., 2003). Therefore, it is tempting to speculate that variations of cAMP levels induced by OR would change the cAMP/cGMP ratio, thereby modulating Slit/Robo activity in ORN axons.

We observed many misrouted ORN axons in Robo1/2-deficient mice but not in Slit1/2-deficient mice, raising the possibility that Slits are not needed for the convergence of axons. However, it has been recently shown that Slit3 was also involved in ORN axon guidance (Cho et al., 2007). Therefore, to fully assess the role of Slits in this process, Slit1/2/ 3-deficient mice will have to be studied.

In Drosophila, a combination of Robo1, Robo2, and Robo3 controls ORN axon sorting to the antennal lobe, and later, Slit influences the positioning of ORN axon terminals in the glomeruli (Jhaveri et al., 2004). In mammals, the development of ORN projections is also a two-step process. First, ORN axons converge to their target region in the $\mathrm{OB}$, probably using axon guidance molecules whose expression level involves OR-cAMP signaling (Imai et al., 2006; Chesler et al., 2007). Second, they determine their specific position into the appropriate glomerulus in an activity-dependent manner with the help of adhesion and guid- ance molecules interacting with OR (Serizawa et al., 2006). Our data favor this hypothesis and strongly suggest that Robol and Robo2 control ORN axon convergence to the OB. Moreover, Slit/Robo signaling regulates the branching of sensory axons in the spinal cord (Ma and Tessier-Lavigne, 2007) and inhibits arborization and synaptogenesis in the zebrafish retina (Campbell et al., 2007). Therefore, Slit/Robo signaling could also control precise axon targeting in the $\mathrm{OB}$, which could explain the presence of additional glomeruli in Slit/Robo mutants. This hypothesis is also consistent with the role of Robo2 in the establishment of the glomerular map in zebrafish (Miyasaka et al., 2005).

\section{References}

Bagri A, Marin O, Plump AS, Mak J, Pleasure SJ, Rubenstein JLR, TessierLavigne M (2002) Slit proteins prevent midline crossing and determine 
the dorsoventral position of major axonal pathways in the mammalian forebrain. Neuron 33:233-248.

Campbell DS, Stringham SA, Timm A, Xiao T, Law MY, Baier H, Nonet ML, Chien CB (2007) Slitla inhibits retinal ganglion cell arborization and synaptogenesis via Robo2-dependent and -independent pathways. Neuron 55:231-245.

Chalasani SH, Sabelko KA, Sunshine MJ, Littman DR, Raper JA (2003) A chemokine, SDF-1, reduces the effectiveness of multiple axonal repellents and is required for normal axon pathfinding. J Neurosci 23:1360-1371.

Chesler AT, Zou DJ, Le Pichon CE, Peterlin ZA, Matthews GA, Pei X, Miller MC, Firestein S (2007) A G protein/cAMP signal cascade is required for axonal convergence into olfactory glomeruli. Proc Natl Acad Sci USA 104:1039-1044.

Cho J, Lépine M, Andrews W, Parnavelas J, Cloutier J-F (2007) Requirement for Slit- 1 and Robo-2 in zonal segregation of olfactory sensory neuron axons in the main olfactory bulb. J Neurosci 27:9094-9104.

Cutforth T, Moring L, Mendelsohn M, Nemes A, Shah NM, Kim MM, Frisen J, Axel R (2003) Axonal ephrin-As and odorant receptors: coordinate determination of the olfactory sensory map. Cell 114:311-322.

de Castro F, Hu L, Drabkin H, Sotelo C, Chédotal A (1999) Chemoattraction and chemorepulsion of olfactory bulb axons by different secreted semaphorins. J Neurosci 19:4428-4436.

Dickson BJ, Gilestro GF (2006) Regulation of commissural axon pathfinding by slit and its Robo receptors. Annu Rev Cell Dev Biol 22:651-675.

Farbman AI, Margolis FL (1980) Olfactory marker protein during ontogeny: immunohistochemical localization. Dev Biol 74:205-215.

Fouquet C, Di Meglio T, Ma L, Kawasaki T, Long H, Hirata T, Tessier-Lavigne M, Chedotal A, Nguyen-Ba-Charvet KT (2007) Robo1 and robo2 control the development of the lateral olfactory tract. J Neurosci 27:3037-3045.

Grieshammer U, Ma L, Plump AS, Wang F, Tessier-Lavigne M, Martin GR (2004) SLIT2-mediated ROBO2 signaling restricts kidney induction to a single site. Dev Cell 6:709-717.

Imai T, Suzuki M, Sakano H (2006) Odorant receptor-derived cAMP signals direct axonal targeting. Science 314:657-661.

Jhaveri D, Saharan S, Sen A, Rodrigues V (2004) Positioning sensory terminals in the olfactory lobe of Drosophila by Robo signaling. Development 131:1903-1912.

Kafitz KW, Greer CA (1999) Olfactory ensheathing cells promote neurite extension from embryonic olfactory receptor cells in vitro. Glia 25:99-110

Komiyama T, Luo L (2006) Development of wiring specificity in the olfactory system. Curr Opin Neurobiol 16:67-73.

Kraut R, Zinn K (2004) Roundabout 2 regulates migration of sensory neurons by signaling in trans. Curr Biol 14:1319-1329.

Ma L, Tessier-Lavigne M (2007) Dual branch-promoting and branchrepelling actions of Slit/Robo signaling on peripheral and central branches of developing sensory axons. J Neurosci 27:6843-6851.

Marillat V, Cases O, Nguyen-Ba-Charvet KT, Tessier-Lavigne M, Sotelo C, Chédotal A (2002) Spatiotemporal expression patterns of slit and robo genes in the rat brain. J Comp Neurol 442:130-155.
Miyasaka N, Sato Y, Yeo SY, Hutson LD, Chien CB, Okamoto H, Yoshihara Y (2005) Robo2 is required for establishment of a precise glomerular map in the zebrafish olfactory system. Development 132:1283-1293.

Mombaerts P, Wang F, Dulac C, Chao SK, Nemes A, Mendelsohn M, Edmondson J, Axel R (1996) Visualizing an olfactory sensory map. Cell 87:675-686.

Monti-Graziadei AG, Graziadei PP (1992) Sensory reinnervation after partial removal of the olfactory bulb. J Comp Neurol 316:32-44.

Nguyen-Ba-Charvet KT, Brose K, Marillat V, Kidd T, Goodman CS, TessierLavigne M, Sotelo C, Chédotal A (1999) Slit2-mediated chemorepulsion and collapse of developing forebrain axons. Neuron 22:463-473.

Nguyen-Ba-Charvet KT, Brose K, Marillat V, Sotelo C, Tessier-Lavigne M, Chédotal A (2001) Sensory axons response to substrate-bound Slit2 is modulated by laminin and cyclic GMP. Mol Cell Neurosci 17:1048-1058.

Nguyen-Ba-Charvet KT, Plump AS, Tessier-Lavigne M, Chédotal A (2002) Slit 1 and Slit2 proteins control the development of the lateral olfactory tract. J Neurosci 22:5473-5480.

Nguyen-Ba-Charvet KT, Picard-Riera N, Tessier-Lavigne M, Baron-Van Evercooren A, Sotelo C, Chedotal A (2004) Multiple roles for slits in the control of cell migration in the rostral migratory stream. J Neurosci 24:1497-1506.

Plump AS, Erskine L, Sabatier C, Brose K, Epstein CJ, Goodman CS, Mason C, Tessier-Lavigne M (2002) Slit1 and Slit2 cooperate to prevent premature midline crossing of retinal axons in the mouse visual system. Neuron 33:219-232.

Ramon-Cueto A, Nieto-Sampedro M (1992) Glial cells from adult rat olfactory bulb: immunocytochemical properties of pure cultures of ensheathing cells. Neuroscience 47:213-220.

Royal SJ, Key B (1999) Development of P2 olfactory glomeruli in P2internal ribosome entry site-tau-LacZ transgenic mice. J Neurosci 19:9856-9864.

Sawamoto K, Wichterle H, Gonzalez-Perez O, Cholfin JA, Yamada M, Spassky N, Murcia NS, Garcia-Verdugo JM, Marin O, Rubenstein JL, Tessier-Lavigne M, Okano H, Alvarez-Buylla A (2006) New neurons follow the flow of cerebrospinal fluid in the adult brain. Science 311:629-632.

Schwarting GA, Raitcheva D, Crandall JE, Burkhardt C, Puschel AW (2004) Semaphorin 3A-mediated axon guidance regulates convergence and targeting of P2 odorant receptor axons. Eur J Neurosci 19:1800-1810.

Serizawa S, Miyamichi K, Takeuchi H, Yamagishi Y, Suzuki M, Sakano H (2006) A neuronal identity code for the odorant receptor-specific and activity-dependent axon sorting. Cell 127:1057-1069.

Strotmann J, Levai O, Fleischer J, Schwarzenbacher K, Breer H (2004) Olfactory receptor proteins in axonal processes of chemosensory neurons. J Neurosci 24:7754-7761.

Wu W, Wong K, Chen J-h, Jiang Z-h, Dupuis S, Wu JY, Rao Y (1999) Directional guidance of neuronal migration in the olfactory system by the protein Slit. Nature 400:331-336.

Zou DJ, Feinstein P, Rivers AL, Mathews GA, Kim A, Greer CA, Mombaerts P, Firestein S (2004) Postnatal refinement of peripheral olfactory projections. Science 304:1976-1979. 